\title{
$\mathrm{VOF}$ 수치해석을 통한 고절수형 위생도기 개발에 관한 연구 안일용, 이영림*, 조우석 ${ }^{++}$, 김진호 ${ }^{++}$ \\ (Manuscript received: Oct, 30, 2012 / Revised: Dec, 10, 2012 / Accepted: Dec, 11, 2012)
}

\section{A Study on Development of High Efficiency Toilets with VOF Numerical Analysis}

\author{
Il Yong $\mathrm{An}^{+}$, Young Lim Lee*, Woo Suck $\mathrm{Jo}^{+}$, Jin Ho Kim ${ }^{++}$
}

\begin{abstract}
When water shortage has been getting worse recently, toilet water-saving is one of the most effective way to solve the water shortage. Therefore, in this study, toilet flushing performance was investigated with VOF(Volume Of Fluid) model to obtain the basic design data for the development of high-efficiency toilets. The result showed that the shorter trapway, the longer the flushing duration time. However, the shorter trapway is found to have disadvantage in exhausting dirt due to relatively weak siphon and higher curvature. Since the remaining water in a trapway appears to help siphon, it is also an important factor in developing high-efficiency toilets. Although higher water level in the water tank shows better performance in flushing, lower water level is preferred to save water. Too low water level may cause dirt to clog the trapway due to relatively weak siphon.
\end{abstract}

Key Words : Toilets(양변기), $\operatorname{VOF}$ (유체체적법), Water saving(물 절약), High efficiency(고절수형), $\mathrm{CFD}$ (전산유체역학)

\section{1. 서 론}

물은 공기와 함께 모든 생명을 유지하는데 꼭 필요한 자원이 다. 지구의 물중 $97 \%$ 는 해수이며, 실제로 사용할 수 있는 물은 $0.00975 \%$ 밖에 되지 않는다 ${ }^{(1)}$. 하지만 그것마저도 급격한 기후 변화와 환경오염으로 사용할 수 있는 물의 양은 점점 더 부족해 지고 있고, 이로 인해 발생되는 많은 문제들은 이루 말할 수 없다. 따라서 물 부족 문제를 해결하는 것은 필수 불가결하다. 물 낭비를 줄이는 동시에 물 절약을 할 수 있는 기술적인 측면 과 제도적인 측면을 갖추는 것은 물 부족을 해결할 수 있는 가 장 효과적인 방법이다. 국내 물 사용량을 용도에 따라 구분했을 때 변기는 $25 \%$, 싱크대는 $21 \%$, 세탁은 $20 \%$, 목욕은 $16 \%$, 세
면은 $11 \%$, 기타는 $7 \%$ 로 변기에서 사용되는 물의 양이 가장 많담. 곧 양변기의 절수기술 개발은 물 절약을 위해서 필수적 이다.

양변기의 절수기술 개발의 핵심은 바로 적은 물의 양으로도 사이펀현상을 효과적으로 발생시키는 것이다. 사이펀현상을 가장 효과적으로 발생시키는 방법은 Suh et $\mathrm{al}^{(3)}$ 이 연구한 가변 식 직선 트랩 양변기 시스템과 같이 직선 모양의 트랩웨이 (Trapway)를 사용하는 것이지만, 다세대 아파트와 같이 수평 으로 오수관이 긴 경우 분뇨배수의 안전성이 확보되지 못한다. 따라서, 기존 $\mathrm{S}$ 모양의 트랩웨이를 유지하면서 효과적으로 사이 펀을 발생시키기 위해서는 CFD(Computational Fluid Dynamics) 를 이용한 유동설계가 필수적이다.

\footnotetext{
* 공주대학교 기계자동차공학부

주소: 331-717 충청남도 천안시 서북구 천안대로 1223-24

$+\quad$ 공주대학교 대학원 기계공학과

$++\quad$ 한국세라믹기술원 도자세라믹센터
}

$\bigotimes$ Comesponding Author E-mail: ylee@kongju.ac.kr 
$\mathrm{CFD}$ 를 이용한 유동설계는 이미 많은 분야에서 사용하고 있 는데, Park and Lee ${ }^{(4)}$ 는 히트펌프를 이용한 고효율 냉풍 대형 건조기 유동 최적설계를 위해 $\mathrm{CFD}$ 를 이용하였고, Hwang and $\mathrm{Lee}^{(5)}$ 는 진공유리의 설계 조건에 따른 단열 성능 연구에 CFD 를 사용하였다.

일반적으로 이동하는 자유표면을 갖는 비압축성 점성유동에 는 고정식 격자계를 이용한 $\mathrm{VOF}$ 를 많이 활용한다. 하지만, 이 러한 VOF를 이용한 양변기 3차원 수치해석에는 많은 시간과 경비가 소모되어 아직 많은 연구가 보고되고 있지는 않는다. 먼저, Wang et al. ${ }^{(6)}$ 은 VOF 모델을 이용한 수치해석을 통하여 서로 다른 모델의 보울 및 트랩웨이에서 시간에 따른 속도와

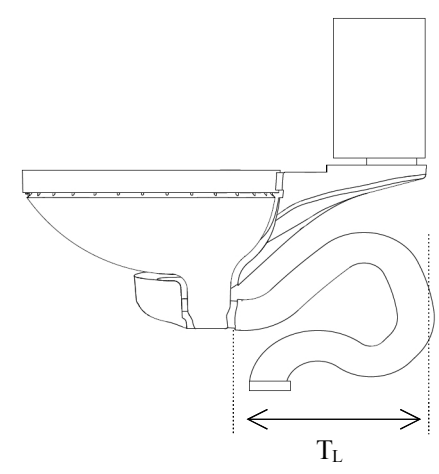

(a) Model 1

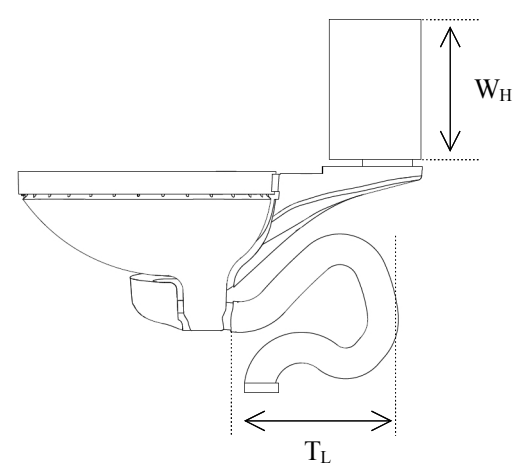

(b) Model 2

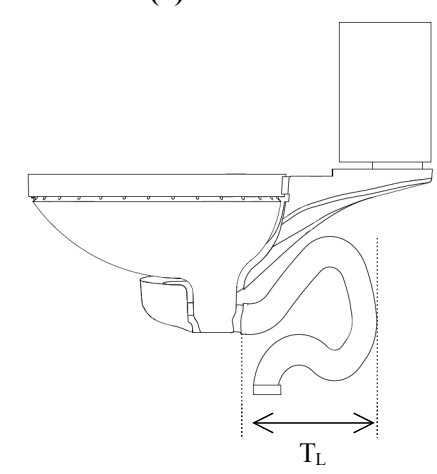

(c) Model 3

Fig. 1 Toilet models with trapway length
압력 변화를 비교 분석하였다. 또한 Zhao et al. ${ }^{(7)}$ 은 VOF 모델 을 이용하여 트랩웨이의 형상에 따른 유동변화를 연구하였고, $\mathrm{Hu}$ et $\mathrm{al}^{\left({ }^{(8)}\right.}$ 은 양변기 내에서 시간에 따른 물의 속도변화를 $\mathrm{VOF}$ 수치해석과 실험을 이용하여 분석하였다.

하지만 아직 고절수형 양변기에 대한 연구는 부족한 실정이 다. 따라서, 본 연구에서는 트랩웨이 형상에 따른 고절수형 양 변기 성능변화를 VOF 모델을 이용하여 고찰하였다. 또한, 트 랩웨이 내에 잔수 영역 존재 유무가 사이펀에 미치는 영향에 대해 알아보았고, 물탱크 내의 물수위에 따른 영향도 알아보았 다. 이를 통해 고절수형 위생도기의 트랩웨이 길이 및 잔수 양, 수위를 최적화할 수 있는 기초 설계자료를 제공하고자 하였다.

\section{2. 수치해석}

본 연구에서는 절수형 양변기의 유동변화를 알아 보기위해 상용소프트웨어인 Fluent V14 VOF 모델을 이용하였다. Fig. 1 은 해석에서 사용된 트랩웨이의 길이에 따른 양변기의 모습을 보여주는데 $\mathrm{T}_{\mathrm{L}}$ 은 트랩웨이의 길이, $\mathrm{W}_{\mathrm{L}}$ 은 물탱크의 수위를 나 타낸다. 각각 트랩웨이의 길이 $\mathrm{T}_{\mathrm{L}}$ 은 Table 1 과 같이 각 모델간 $20 \%$ 의 변화로 $0.33 \mathrm{~m}, 0.28 \mathrm{~m}, 0.23 \mathrm{~m}$ 로 주었다. 이때 수위 $\mathrm{W}_{\mathrm{H}}$ 는 모두 $0.238 \mathrm{~m}$ 로 가정하였다. 또한 물수위에 따른 양변기 유 동해석을 위하여 트랩웨이 길이 $\mathrm{T}_{\mathrm{L}}$ 이 $0.28 \mathrm{~m}$ 일 때 각 모델의 수위 $\mathrm{W}_{\mathrm{L}}$ 을 Table 1 과 같이 $0.238 \mathrm{~m}, 0196 \mathrm{~m}, 0.146 \mathrm{~m}$ 로 가정하

Table 1 Length of trapway and water level of water tank with models

\begin{tabular}{c|c|c}
\hline \hline Model No. & TL $(\mathrm{m})$ & WH $(\mathrm{m})$ \\
\hline 1 & 0.33 & 0.238 \\
\hline 2 & 0.28 & 0.238 \\
\hline 3 & 0.23 & 0.238 \\
\hline 4 & 0.28 & 0.196 \\
\hline 5 & 0.28 & 0.146 \\
\hline
\end{tabular}

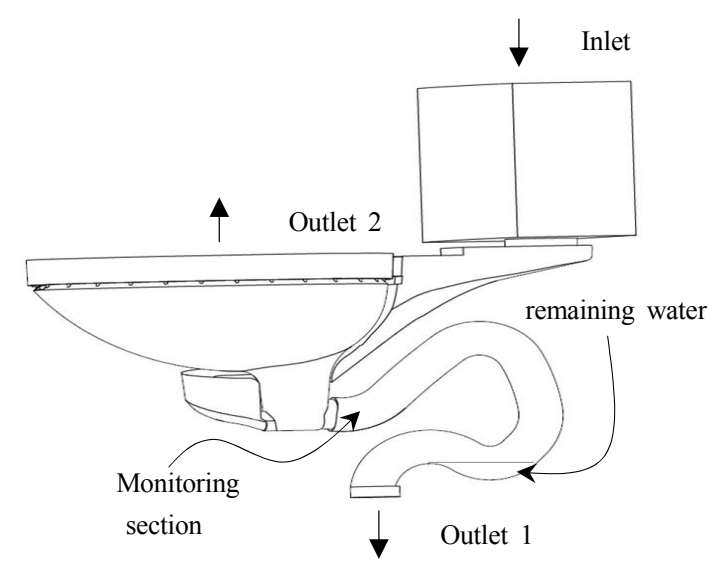

Fig. 2 Boundary conditions of toilet 


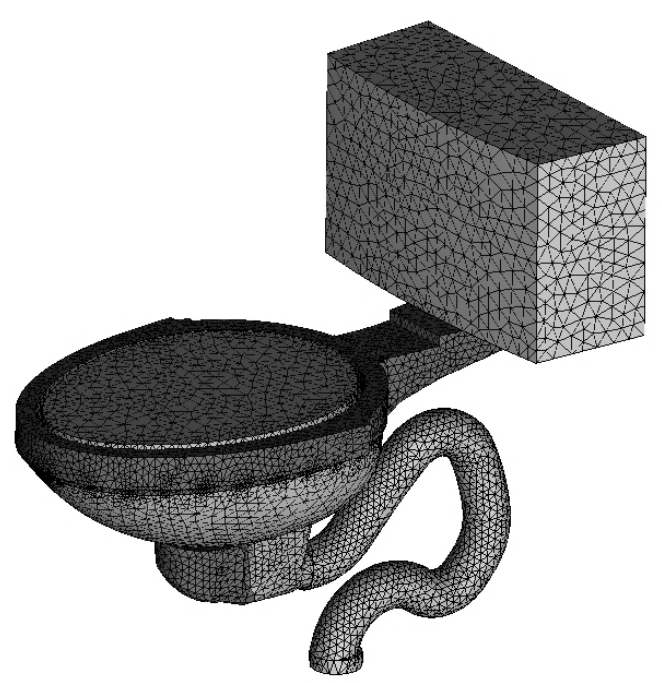

Fig. 3 Mesh system for toilet

였다. 해석에서 사용된 트랩웨이는 Fig. 2와 같이 잔수 영역을 가지도록 고안되었는데, 잔수 영역에 따른 유동해석을 위하여 모델 2 를 기준으로 해석을 진행하였다. 해석에서 사용된 경계 조건은 Fig. 2와 같다. 물탱크 덮개와 물이 배출되는 트랩웨이 배관 끝은 대기압으로 압력경계조건을 지정해 주었다. 또한 양 변기 덮개에 해당하는 부분 역시 압력경계조건으로 지정해 주 었다.

\section{1 지배 방정식}

본 연구에서 고려된 유체유동은 3 차원, 비압축성, 비정상상 태 이상 난류유동으로 난류모델로는 Shinh et al. ${ }^{(9)}$ 이 제안한 Realizable k- $\varepsilon$ 난류 모델을 사용하였다. 지배방정식은 NavierStokes 방정식을 평균하여 식 (1)과 같은 Reynolds averaged Navier-Stokes(RANS) 방정식을 사용하였다 ${ }^{(10)}$.

$$
\begin{aligned}
& \frac{\partial\left(\rho \overline{u_{i}}\right)}{\partial t}+\frac{\partial\left(\rho \overline{u_{i}} \bar{u}_{j}\right)}{\partial x_{j}} \\
= & -\frac{\partial \bar{p}}{\partial x_{i}}+\frac{\partial}{\partial x_{j}}\left[\mu\left(\frac{\partial \bar{u}_{i}}{\partial x_{j}}+\frac{\partial \bar{u}_{j}}{\partial x_{i}}-\frac{2}{3} \delta_{i j} \frac{\partial \overline{u_{m}}}{\partial x_{m}}\right)\right] \\
& +\frac{\partial}{\partial x_{j}}\left(-\rho \overline{u_{i} \bar{u}_{j}}\right)
\end{aligned}
$$

\section{2 격자 시스템}

Fig. 3은 양변기 모델 유동해석을 위한 격자 시스템을 보여 준다. 3 차원, 비압축성, 비정상상태, 이상 난류유동은 일반적으 로 해석시간이 많이 요구되므로, 모델의 형상을 정확하게 표현 하는 한도 내에서 격자수를 최소화 하여 약 20 만개의 사면체 격자를 사용하였다.

\subsection{VOF 모델}

본 연구에서는 Hirt and Nichols ${ }^{(11)}$ 가 제안한 VOF 방법을 채택하였다. $\mathrm{VOF}$ 는 임의의 셀에서 유체가 차지하는 체적 분율 (Volume fraction)을 정의하고, 식 (2)와 같은 체적 분율 F에 대한 전달 방정식을 풀어서 시간에 따른 영역의 변화를 표현하 는 방법이다 ${ }^{(12)}$.

$$
\frac{\partial F}{\partial t}+v \cdot \nabla F=0
$$

\section{3. 실험결과 및 고찰}

\section{1 트랩웨이 형상에 따른 양변기 성능변화}

Fig. 2 의 트랩웨이 모니터링 지점에서 시간에 따른 단면 평균

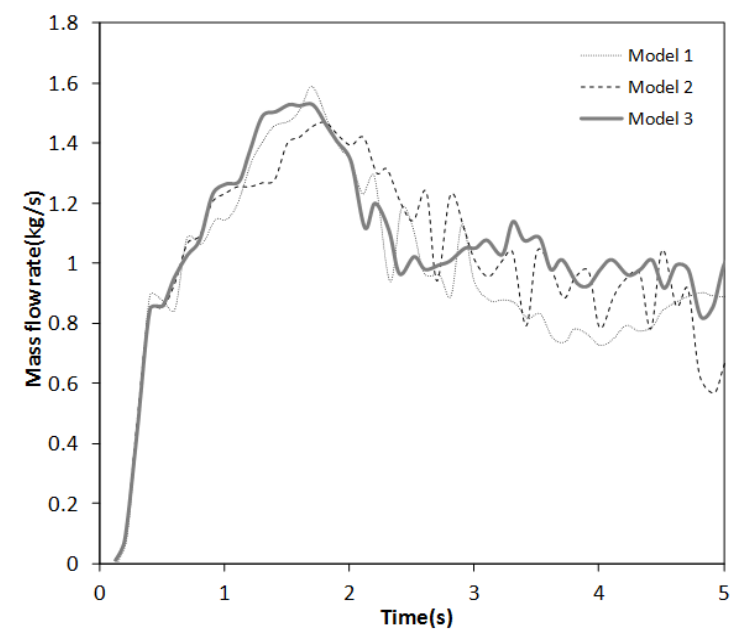

Fig. 4 Variation of mass flow rate with time for each model

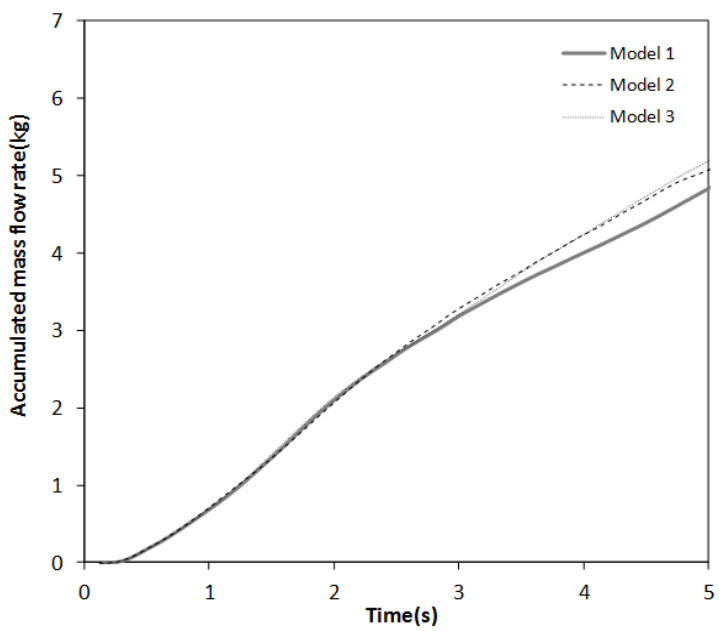

Fig. 5 Variation of accumulated mass flow rate with time for each model 
유량 변화를 Fig. 4에 나타내었다. 세정이 시작되고 사이펀이 발생하기 전인 약 $0.8 \mathrm{~s}$ 까지는 모든 모델이 거의 동일하게 유량 이 증가 하는 것을 알 수 있다. 하지만 그 이후에는 트랩웨이 길이와 곡률에 따른 사이펀 변화로 각 모델의 유량은 서로 달라 지게 된다. 모델 1 의 경우 사이펀에 의해 보울 내의 잔수가 하 강하기 시작하는 시간은 약 $1.1 \mathrm{~s}$ 이고, 약 $1.7 \mathrm{~s}$ 에 $1.59 \mathrm{~kg} / \mathrm{s}$ 로 최 대유량에 도달한다. 모델 2의 경우는 사이펀에 의해 잔수 하강 시작 시간은 약 $1.5 \mathrm{~s}$ 이고 약 $1.8 \mathrm{~s}$ 에 $1.47 \mathrm{~kg} / \mathrm{s}$ 의 최대유량이 된 다. 또한 모델 3 의 경우는 잔수 하강 시작 시간은 약 $1.1 \mathrm{~s}$ 이고 약 $1.7 \mathrm{~s}$ 에 $1.53 \mathrm{~kg} / \mathrm{s}$ 의 최대유량을 보여준다. 그러므로, 3 개의 모델 중 모델 1 이 가장 높은 순간 최고유량을 발생시키지만 모 델 1 은 사이펀 발생 후 약 $2 \mathrm{~s}$ 만에 사이펀이 약해져 다시 보울로

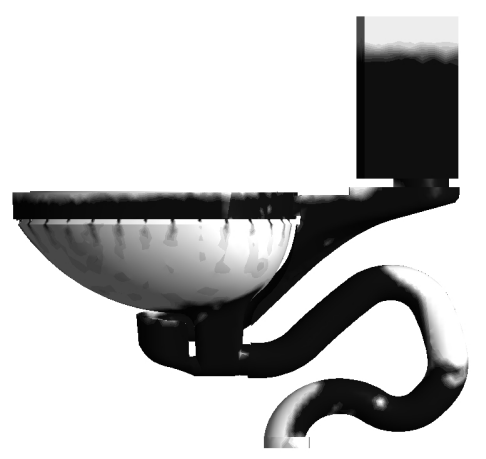

(a) $1 \mathrm{~s}$

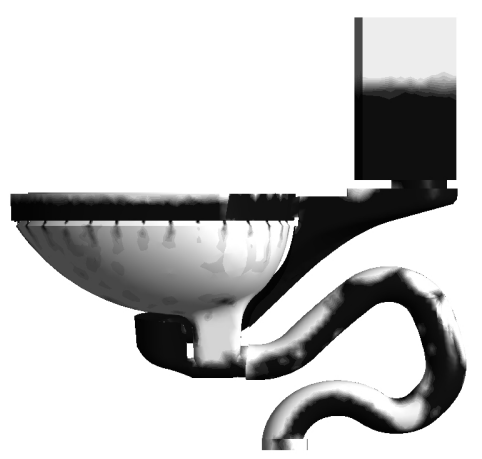

(b) $3 \mathrm{~s}$

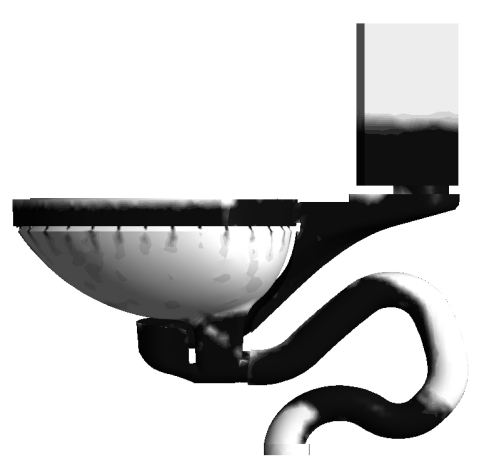

(c) $5 \mathrm{~s}$

Fig. 6 Variation of water volume fraction with time for model 1
물이 차오르게 된다. 이에 반해, 모델 2는 사이펀이 약 $3.5 \mathrm{~s}$ 동 안 지속되고 모델 3은 지속적으로 사이펀이 발생하게 된다. 일 반적으로 양변기 세정 성능은 최고유량 뿐만아니라 사이펀 지 속시간도 동시에 고려해야하므로 모델 1 보다 모델 2 혹은 3 이 지속시간 측면에선 우수하다.

한편, Fig. 5에 시간에 따른 각 모델의 적산유량(acculmulated mass flow rate) 변화를 나타냈다. 세정이 시작된 후 약 $3 \mathrm{~s}$ 까지 는 각 모델 모두 거의 동일한 적산유량을 보여준다. 하지만 $3 \mathrm{~s}$ 이후 모델 1 의 사이펀 현상이 사라지면서 모델 2와 모델 3에 비해 모델 1 의 적산유량은 현저히 줄어들게 된다. 모델 2 의 경 우도 사이펀이 지속적으로 발생하는 모델 3에 비해 시간이 지 날수록 적산유량 차이도 조금씩 적어지는 것을 알 수 있다. 각

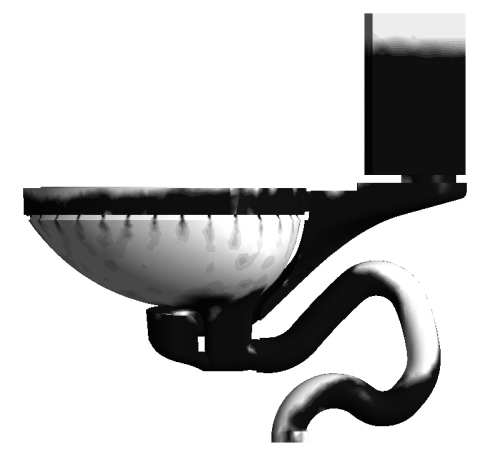

(a) $1 \mathrm{~s}$

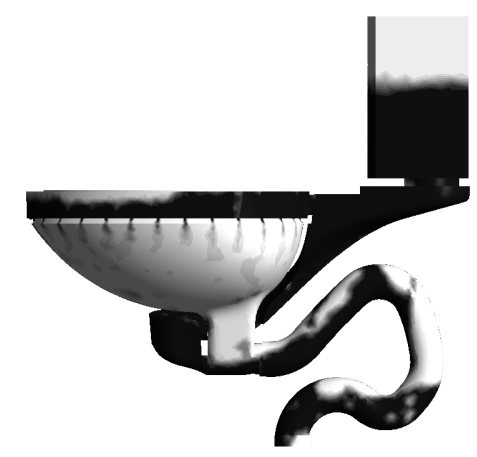

(b) $3 \mathrm{~s}$

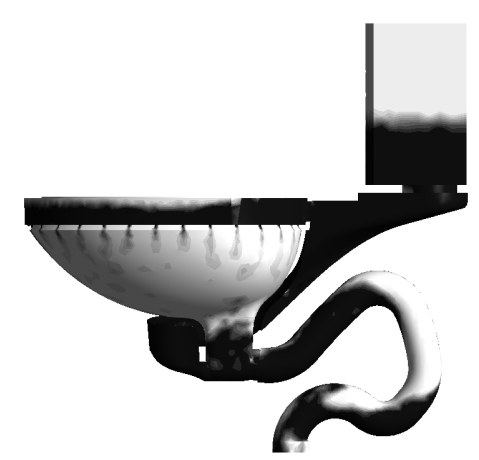

(c) $5 \mathrm{~s}$

Fig. 7 Variation of water volume fraction with time for model 2 
모델의 시간에 따른 물 체적 분율을 Fig. 6, Fig. 7, Fig. 8에 나타냈다. 세정 시작 이후 약 $1 \mathrm{~s}$ 에서의 물 체적 분율은 모델과 관계없이 거의 동일한데, 이것은 질량유량이나 적산유량이 약 $1 \mathrm{~s}$ 까지는 거의 변화가 없음에 기인한다. 세정 시작 후 약 $3 \mathrm{~s}$ 에 서는 모든 모델에서 사이펀으로 인한 잔수 배출작용이 활발히 일어나고 있다. 하지만 모델 1과 모델 2의 경우는 각각 약 3.1s 와 $4.8 \mathrm{~s}$ 에 사이펀이 약해져 약 $5 \mathrm{~s}$ 후에는 보울 쪽으로 다시 잔 수가 차오르게 된다. 이것은 Fig. 6(c)와 7(c)의 보울 내 잔수 위치로부터 확인할 수 있다. 반면, 모델 3 의 경우는 $5 \mathrm{~s}$ 경과 후 에도 사이펀 현상이 지속적으로 일어나 보울 내에 잔수가형성 되지 않고 왕성한 배출이 일어나고 있음을 알 수 있다.

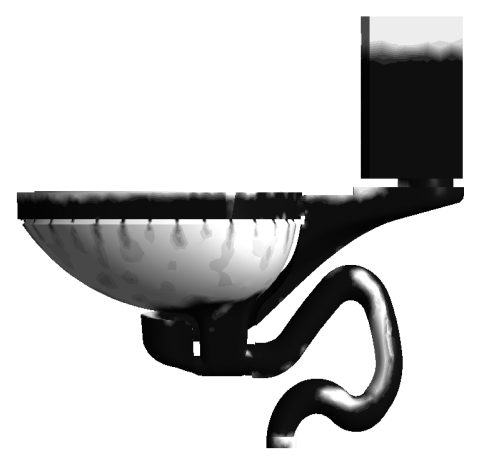

(a) $1 \mathrm{~s}$

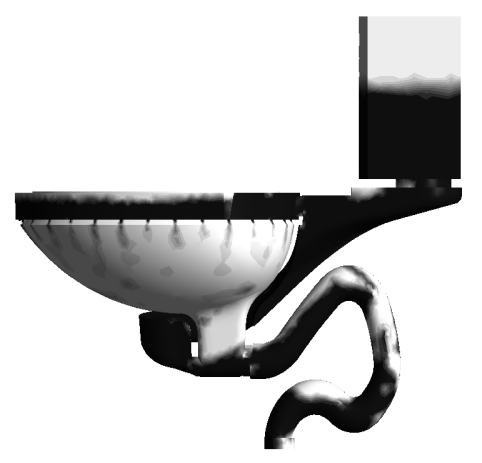

(b) $3 \mathrm{~s}$

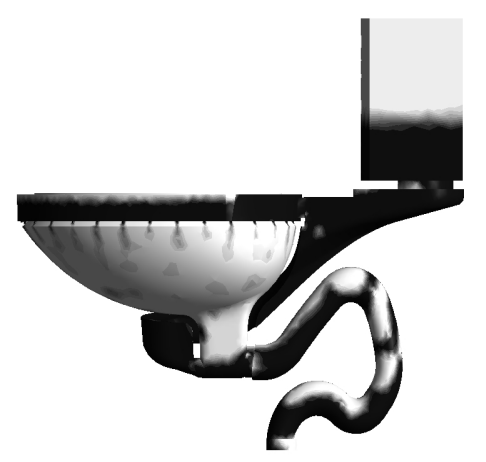

(c) $5 \mathrm{~s}$

Fig. 8 Variation of water volume fraction with time for model 3

\section{2 트랩웨이 잔수 영역 유무에 따른 양변기 성능변화}

Fig. 9는 모니터링 지점에서 모델 2의 시간에 따른 유량변화 를 보여주는데 트랩웨이 잔수 유무에 따른 세정 성능 변화를 나타낸다. 약 $1 \mathrm{~s}$ 까지는 두 경우 모두 거의 동일하게 유량이 증 가한다. 하지만 $1 \mathrm{~s}$ 이후 트랩웨이 내에 잔수가 없는 경우는 약 $1.2 \mathrm{~s}$ 만에 사이펀으로 인한 보울 내 잔수가 하강하기 시작하여 약 $0.5 \mathrm{~s}$ 만에 최대유량 $1.57 \mathrm{~kg} / \mathrm{s}$ 에 도달하고 잔수가 있는 경우 는 약 $1.5 \mathrm{~s}$ 만에 보울내 잔수가 하강하기 시작하여 약 $0.3 \mathrm{~s}$ 만에 최대유량 $1.47 \mathrm{~kg} / \mathrm{s}$ 에 이른다. 이것은 잔수가 있는 경우 트랩웨 이 내의 물을 추가적으로 가속하기 위한 시간 지연 현상에 기인 하는 것으로 사료된다. 보울내에 잔수가 모두 배출된 후, 트랩 웨이 잔수가 없는 경우는 지속적으로 트랩웨이를 채울 수 있는 충분한 유량이 확보되지 않기 때문에 약 $3.6 \mathrm{~s}$ 에 보울 내로 다시 물이 차오르게 된다. 하지만 트랩웨이 내에 잔수가 있는 경우는

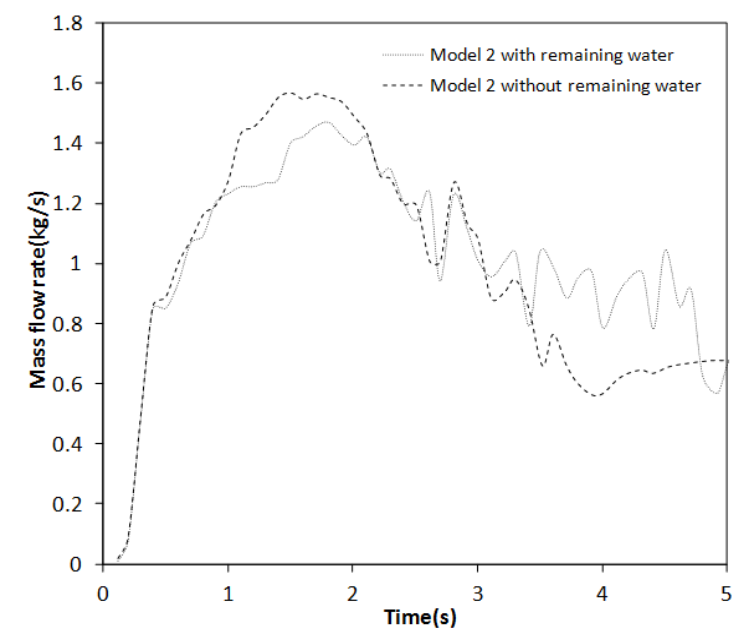

Fig. 9 Variation of mass flow rate with time for model 2

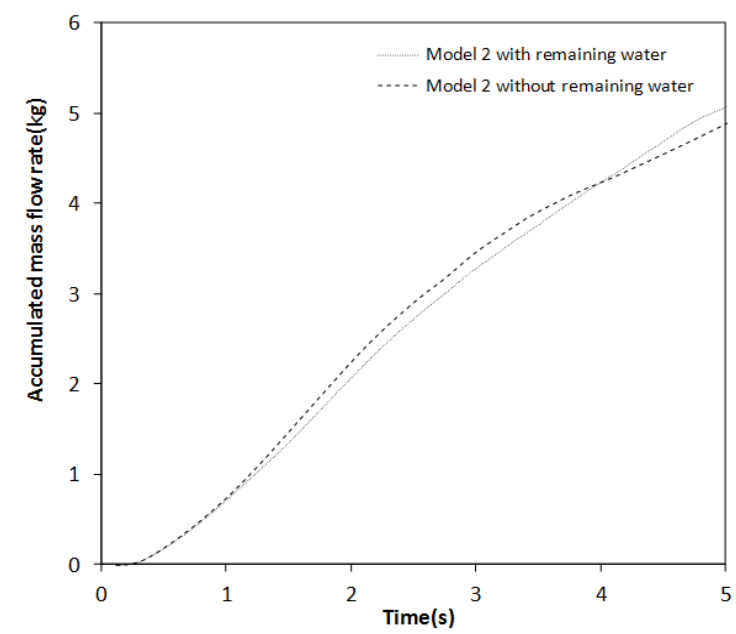

Fig. 10 Variation of accumulated mass flow rate with time for model 2 
약 $4.8 \mathrm{~s}$ 만에 보울 내로 다시 물이 차오르게 되어 트랩웨이 내 추가적인 잔수로 인해 사이펀이 더 오래 지속되었음을 의미한 다. 이것은 Fig. 7의 잔수가 있는 경우와 Fig. 11의 잔수가 없는 경우의 물 체적 분율을 통해서도 알 수 있다.

Fig. 10은 트랩웨이 내에 잔수가 있는 경우와 없는 경우의 시간에 따른 적산유량 변화를 보여준다. 약 $1 \mathrm{~s}$ 까지는 두 경우 모두 거의 동일한 유량 증가를 나타내나 그 이후 약 $1 \mathrm{~s}$ 에서 약 $4 \mathrm{~s}$ 까지는 잔수가 없는 경우가 있는 경우보다 더 강력한 사이펀 을 발생시켜 더 높은 적산유량을 발생시킨다.하지만 그 이후 잔수가 있는 경우가 잔수가 없는 경우보다 사이펀 지속시간이 길어 더 많은 적산유량을 기록한다. 이것은 잔수가 없는 경우

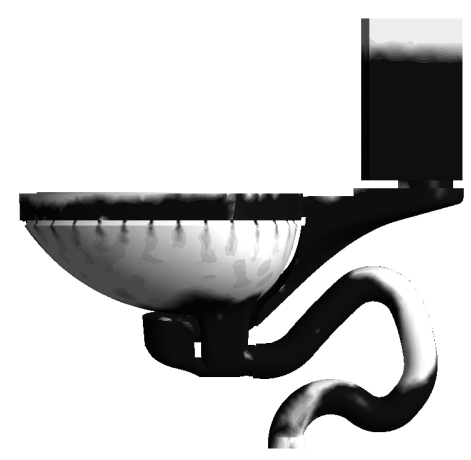

(a) $1 \mathrm{~s}$

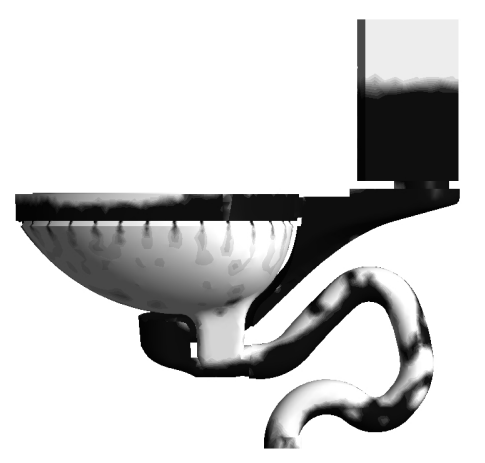

(b) $3 \mathrm{~s}$

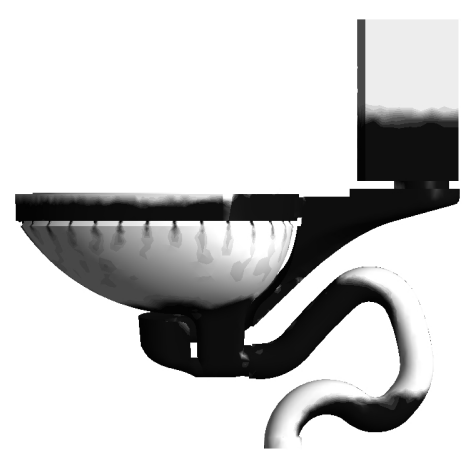

(c) $5 \mathrm{~s}$

Fig. 11 Variation of water volume fraction with time for model 2 without remaining water
약 $3.6 \mathrm{~s}$ 에 사이펀 현상이 약화되어져 $3.6 \mathrm{~s}$ 에서 $5 \mathrm{~s}$ 사이의 적산 유량이 $0.96 \mathrm{~kg}$ 인 반면 잔수가 있는 경우는 약 $4.8 \mathrm{~s}$ 까지 사이펀 이 지속되어 같은 시간동안 적산유량이 $1.32 \mathrm{~kg}$ 에 달하기 때문 이다. 따라서 $5 \mathrm{~s}$ 동안 전체 적산유량은 잔수가 없는 경우 $4.89 \mathrm{~kg}$ 이고 잔수가 있는 경우 $5.08 \mathrm{~kg}$ 으로써 잔수가 있는 경우가 더 많은 유량을 배출시킨 것을 알 수 있다.

\section{3 물탱크 물수위에 따른 양변기 성능변화}

Fig. 12는 Fig. 2에서 나타낸 모니터링 지점에서의 시간에 따른 단면 평균유량 변화를 나타낸다. 여기서 모델 2, 4 및 5는 물탱크 수위가 각각 $0.238 \mathrm{~m}, 0.196 \mathrm{~m}, 0.146 \mathrm{~m}$ 이다. 각 모델의 시간에 따른 유량은 사이펀으로 인해 급격히 증가하다 최고유 량에 도달한 후 감소하게 된다. 하지만 약 $3 \mathrm{~s}$ 이후에는 모델 4 의 사이펀 강도가 급격히 감소하는데 비해 모델 2와 모델 5는

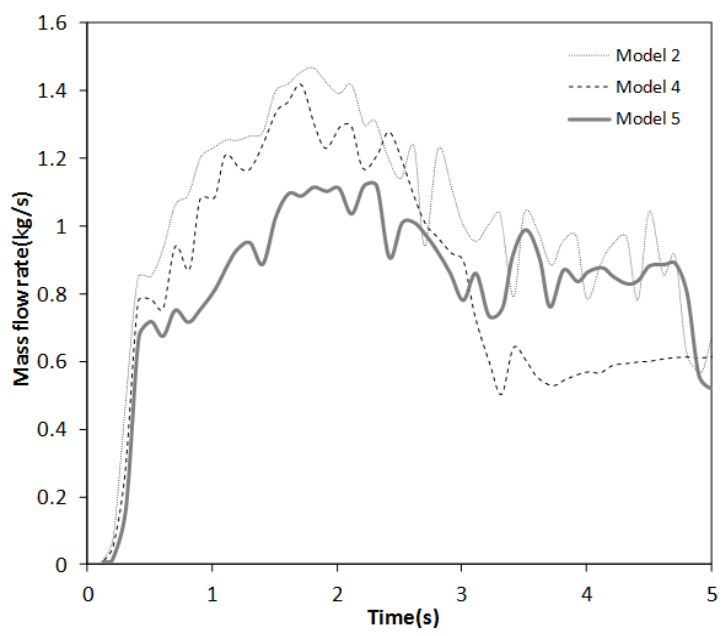

Fig. 12 Variation of mass flow rate with time for each model

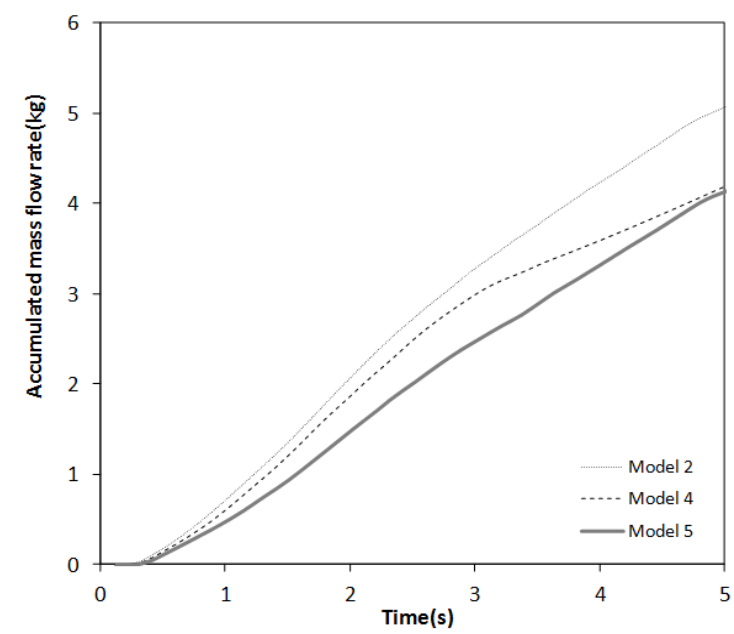

Fig. 13 Variation of accumulated mass flow rate with time for each model 
비교적 양호한 유량을 보여 준다. 이것은 단순히 수위가 높아 정수압이 강할수록 사이펀이 오래 지속되지 않는다는 것을 의 미한다. 한편, 모델 5의 경우 사이펀 강도가 상대적으로 낮아 보울 내의 잔수를 효과적으로 배출시키기 어려울 것으로 보인다.

Fig. 13에 시간에 따른 적산 유량을 나타내었다. 약 $3 \mathrm{~s}$ 까지는 수위에 비례하여 유량이 증가하였으나 그 이후부터는 모델 4의 사이펀 강도가 현저히 낮아짐으로 인해 유량이 다른 모델 대비 급격히 줄어든다. 결국 약 $5 \mathrm{~s}$ 에는 모델 4 와 모델5가 거의 동일 한 적산유량을 보여준다. 수위에 따른 보울 내의 잔수 배출을 살펴보기 위하여 Fig. 14와 Fig. 15에 모델 4와 모델 5의 시간 에 따른 물 체적 분율 변화를 나타냈다. 모델 4 를 살펴보면 $3 \mathrm{~s}$ 까지 강력한 사이펀으로 보울 내의 모든 잔수가 배출되고 약

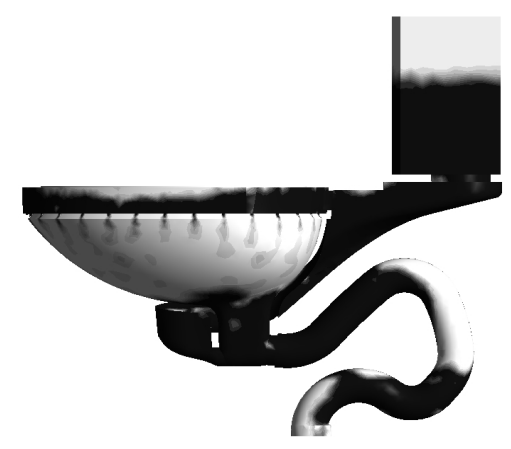

(a) $1 \mathrm{~s}$

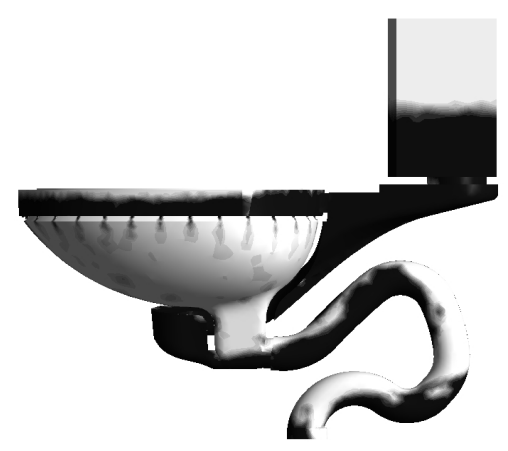

(b) $3 \mathrm{~s}$

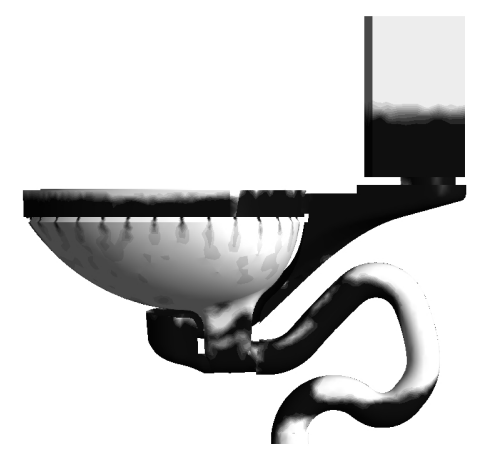

(c) $5 \mathrm{~s}$

Fig. 14 Variation of water volume fraction with time for model 4
$3.3 \mathrm{~s}$ 에는 약해진 사이펀으로 다시 잔수가 보울 내로 차오르는 것을 볼수 있다. 이에 반해 모델 5는 꾸준한 적산유량 배출을 보인 것과는 달리 사이펀 강도가 상대적으로 약하여 보울 내의 잔수가 $5 \mathrm{~s}$ 동안 한 번도 트랩웨이 연결파이프 밑바닥까지 하강 하지 않는다. 이는 모델 5의 경우 보울 내의 오물이 완전히 배 출되지 않고 세정 후에도 보울 내에 잔류할 가능성이 높음을 의미한다.

\section{4. 결 론}

본 논문에서는 고절수형 양변기 개발을 위한 기초 연구로써 트랩웨이 길이, 잔수 유무, 물탱크 수위에 따른 세정 성능 변화

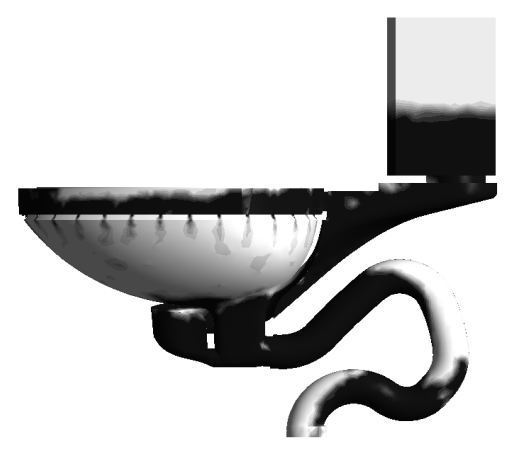

(a) $1 \mathrm{~s}$

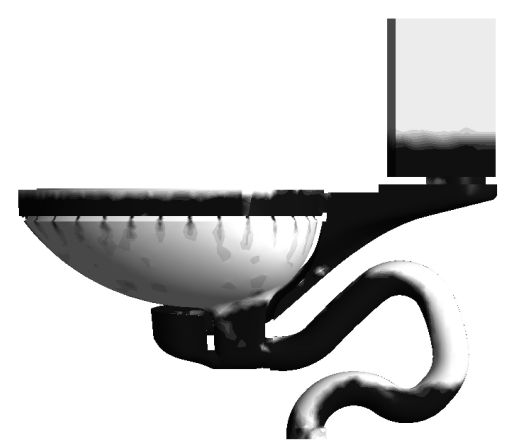

(b) $3 \mathrm{~s}$

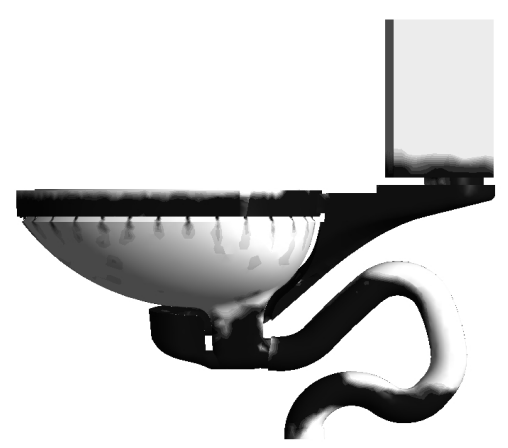

(c) $5 \mathrm{~s}$

Fig. 15 Variation of water volume fraction with time for model 5 
를 VOF 수치해석을 통해 알아보았다. 본 연구를 통해 얻은 결 론은 다음과 같다.

(1) 트랩웨이가 길어질수록 사이펀의 강도는 증가하는 반면 사 이펀 지속시간은 줄어든다. 따라서, 트랩웨이가 긴 양변기 의 배출유량은 트랩웨이가 짧은 양변기에 비해 적어지게 된다. 하지만, 트랩웨이가 짧은 양변기의 경우 사이펀 지속 시간은 길어지나 상대적으로 낮은 사이펀 강도나 심한 곡 률로 인해 오물 배출이 원활하지 않을 수 있기 때문에 트랩 웨이 길이에 대한 최적화가 필요하다.

(2) 트랩웨이 내의 잔수는 사이펀 강도는 다소 감소시키나 사 이펀 지속시간을 길게 해주는 효과가 있다. 따라서, 양변기 세정 성능을 극대화하기 위해서는 트랩웨이 내의 잔수 설 계도 최적화해야 한다.

(3) 물탱크 수위가 높을수록 정수압이 강해져 사이펀 강도가 강해진다. 하지만 절수를 위해 수위를 너무 낮추게 되면 사 이펀 강도가 충분하지 않아 오물 배출이 어렵게 된다. 또한 강한 사이펀 이후에 유량이 급격히 줄어드는 현상이 없고 꾸준히 물이 배출되어 결과적으로 절수 효과도 사라질 수 있다.

따라서 향후 트랩웨이 형상 및 길이, 잔수 설계, 물탱크 수위 에 대한 실험과의 검증을 통해 고절수형 위생도기 개발이 필요 하다.

\section{후 기}

본 연구는 2012년도 한국세라믹기술원 정부출연연구개발사 업 지원에 의하여 수행되었습니다.

\section{References}

(1) Marq, D. V., 2001, Water: The Fate of Our Most Precious Resource, Mariner Books, Canada.

(2) Kim, J. B., 2007, "Domestic Water Demand Model," Korea Water Resources Corporation, Vol. 41, pp. 31 37.

(3) Suh, K. W., Won, Y. J., and Lee, Y. H., 2009, “A Study on the Water Saving Device Using a Variable
Position Straight Trap in Water Closet System," The Society of Air-conditioning and Refrigerating Engineers of Korea, Vol. 41, pp. 465 470.

(4) Park. S. J., and Lee. Y. L., 2011, “Optimal Flow Design of High-efficiency, Cold-flow, and Large-size Heat Pump Dryer," Journal of the Korean Society of Manufacturing Technology Engineers, Vol. 20, No. 5, pp. 547 552.

(5) Hwang. I. S., and Lee. Y. L., 2012, "A Study of Adiabatic Performance for Vacuum Glazing with Design Conditions," Journal of the Korean Society of Manufacturing Technology Engineers, Vol. 21, No. 4, pp. 582 587.

(6) Wang, Y. H., Xiu, G. J., and Tan, H. S., 2011, “CAD and CAE Analysis for Sipohn Jet Toilet," Physics Procedia, Vol. 19, pp. 472 476.

(7) Zhao, S. Y., Liu, Z. J., and Peng, Z. W., 2008, "Optimized Design of Toilet Siphon Pipeline Based on Fluent and Its Validated Test," Journal of System Simulation, Vol. 20, No. 16, pp. 4412 4416.

(8) Hu, J. G., Sun, Y. S., and Liu, M. J., 2008, "Numerical Simulation of Two-phase Flow in Wash-down Toilet Flush Process," Journal of System Simulation, Vol. 20, No. 6, pp. 1599 1602.

(9) Shih, T. H., Liou, W. W., Shabbir, A., and Zhu, J. A., 1995, “A New k- $\varepsilon$ Eddy-Viscosity Model for High Reynolds Number Turbulent FLows Model Developement and Validation," Computer Fluids, Vol. 24, No. 3, pp. 27 238.

(10) ANSYS, 2012, ANSYS FLUENT User's Manual Version 14.0, ANSYS Inc.

(11) Hirt, C. W., and Nichols, B. D., 1981, "Volume of Fluid (VOF) Method for the Dynamics of Free Boundaries," J. Computational Physics, Vol. 39, Issue 1, pp. 201 225.

(12) Shin, S. H., and Lee, W. I., 1997, "Finite Element Analysis of Flow with Moving Free Surface by Volume of Fluid Method," Transactions of the KSME B, Vol. 21, No. 9, pp. 1230 1243. 